\title{
How to Promote Product Quality?
}

\author{
Gao Su, Associate Professor \\ School of Management \\ Fujian University of Technology \\ Fuzhou City, Fujian, China. \\ 46006075@qq.com
}

\author{
Li-Shan Chen, Associate Professor \\ School of Management \\ Fujian University of Technology \\ Fuzhou City, Fujian, China. \\ sun56@ms8.hinet.net
}

\author{
Lin Shenghao \\ New York University \\ New York, USA
}

\begin{abstract}
There is a large amount of literature discussing the issues regarding promotion and how important the key factors are. Most of the existing researches use the exact data to analyze problems, but there always exist various uncertainties in realworld problems. It is usually hard to define a traditional quantitative approach to solve these problems. Our research incorporates method to identify affecting promotion and to analyze the pairwise relationships of these factors via the relevant mathematical models. According to the results of this study, we conclude that employing the proposed approach to identify promoting to provide top managers with reference to draw up the marketing strategies.
\end{abstract}

Keywords-Key words: Product Quality, Artificial Intelligence, Quantitative Method, Marketing Strategy

\section{INTRODUCTION}

Since the Reform and Opening, China's economic develops rapidly and its people's living standards continue to improve, with the number and variety of consumer goods increasing. According to the data released by the Ministry of Commerce on January 20, 2017, the total retail sales of social consumer goods reached 33.2 trillion yuan in 2016, an increase of $10.4 \%$ over the same period of last year. The contribution rate of consumption to national economic growth was $64.6 \%, 4.7$ percentage points higher than the data of 2015 .

Such a large market has attracted many domestic and foreign enterprises, among which the competition is intensifying, and promotion as a commonly-used method to stimulate consumers to purchase is highly concerned. Promotion refers to the use of various short-term incentives to encourage consumers to purchase their products or services [1]. The real purpose of the promotion is to provide customers with more product value, stimulate customer demand, and attract more new and old customers to buy the brand products [2]. Practice has proved that different promotional activities will give consumers different perceptions, and the resulting promotional effect is also very different.

The success of using promotional activities directly relates to the survival of enterprises. Most companies use promotions casually, which will affect the effectiveness of promotions. Enterprises should take the market environment into consideration, making the choice and strategy to match the promotional methods and strategies to ensure that promotional activities can be carried out smoothly, and ultimately achieve the objectives of the enterprise.

\section{THEORETICAL BACKGROUND}

In recent years, domestic and foreign scholars concerned about the use of corporate promotion from different angles, so the overall research is relatively rich.

Zhang Yan, Peng Pinzhi [3] proposed that in the current information age, promotion is the most important mouthpiece of marketing, which is in the essential place of the product and information communication among the enterprise, dealer retailers and consumers. Promotion strategy is not only a strategic issue of marketing, but also import aspect of business development strategy.

Zhang Wangqiang and Chen Rong [4] using the hotel as an experimental scene, from the perspective of behavior to build research framework, state that the higher the perceived value of the integral promotion, the higher the effectiveness of the integral promotion, and that the lower the perceived risk of the consumer, the lower the value of the customer's promotion.

Dong Yanni, Li Wei [5] find that the purchase of gifts can better reduce the perceived risk of consumers and improve consumer perceived value, thereby increasing their willingness to buy.

Therefore, through the establishment of a path model of post-crisis promotion's influence on the consumption willing, they find the better promotion method to improve consumption willing after crisis: non-money promotion is better than money promotion on market recovery.

Zeng Yurong, Le Wei, Zhao Feng [6] think that under the whole store promotion and single product promotion, two different forms of promotion, there is a significant difference between the consumer's internal reference price in the willingness to pay and the reasonable price, and that reference price of single product promotion under the whole store is even lower.

The degree of intervention and the price sensitivity of the consumers have a significant effect on the consumer reference 
price. Hence, the use of the promotion form should be more prudent, otherwise the consumers reference price will reduce the consumer's judgment on the real price, thereby reducing the effect of promotions.

\section{METHODOLOGY}

\section{A. Steps of Applying DEMATEL}

Step 1: Define the influential factors in the research problem and design a survey that can reflect relations among these factors, which means this study will evaluate the influential level between each pair of factors, and in the meanwhile establish the quantitative table of these relations. We can use 1, 2, 3 and other numbers to describe the relating levels from weak to strong. The survey designed will ask people to answer questions about factor relations based on their subjective opinions, using the number symbols mentioned above.

Step 2: Organize and collect questionnaires. Build direct relation n-times-n matrix according to the relation scales of pairs, where the entry corresponds to the influence of the factor on factor.

Step 3: Build the standardized direct influence matrix.

Step 4: Using the standardized matrix, by formula, determine the overall influence matrix.

Step 5: Calculate the sum of each row, denoted the sum of each column, denoted the sum of every row in the matrix, which shows the level of the factors being influenced by other factors directly or indirectly.

Step 6: Calculate the center degree and reason degree for each factor. Using and we obtain from step 5, known that show the strength of relation among factors (center degree), show the level of factors influencing other factors and being influenced by other factors (reason degree), we can use the value to analyze influential factors in the problem.

\section{RESULT}

This article selects five experts including a well-known beverage sales manager, two retail sales directors and two retail store managers as the object of the survey. According to problems that enterprises may face during operating promotions, this study determines the influential factors of this promotion, and defines them as following: product brand (F1), product category $(\mathrm{F} 2)$, merchandise display $(\mathrm{F} 3)$, celebrity effect (F4), public relations activity (F5), salesperson quality (F6), media selection (F7), POP advertising (F8) Activities (F9), business promotion activities (F10). The questionnaire studies the importance of the ten factors and their relations between each other.

Research result was shown as Figure 1.

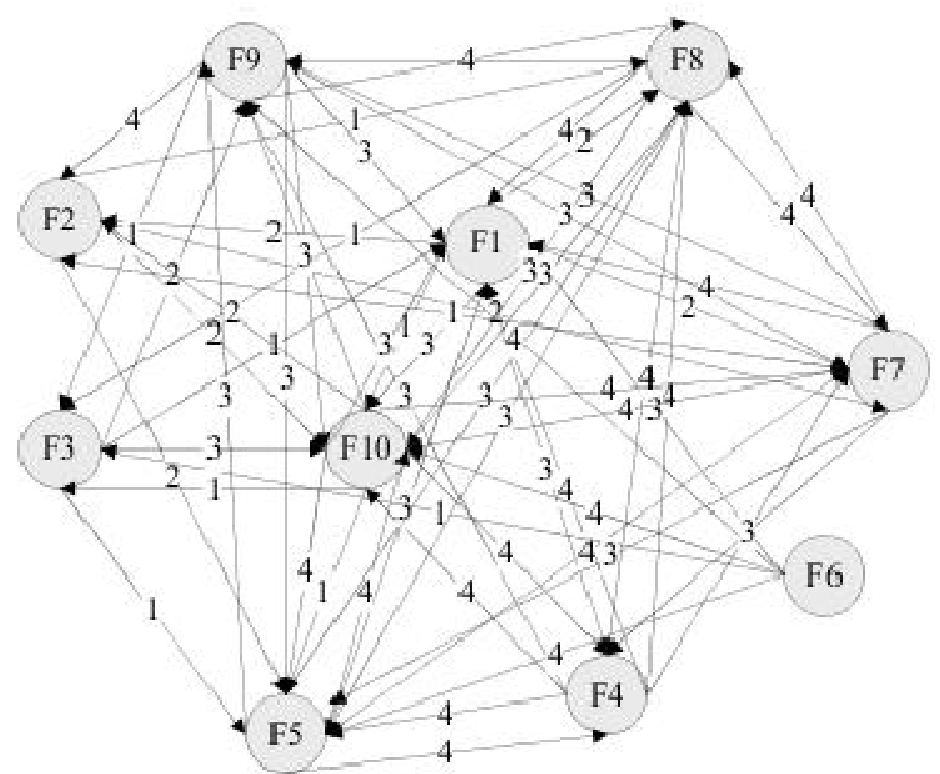

FIGURE 1. FACTOR RELATION

\begin{tabular}{|c|c|c|c|c|}
\hline & D & $\mathrm{R}$ & $\mathrm{D} \perp \mathbf{R}$ & $\mathrm{DR}$ \\
\hline F1 & 0.734 & 0.927 & 1.662 & -0.193 \\
\hline $\mathrm{F} 2$ & 0.499 & 0.871 & 0.89 & 0048 \\
\hline $\mathrm{F3}$ & 0.362 & 0.452 & 0.814 & -0460 \\
\hline $\mathrm{F} 4$ & 0.763 & 0.822 & 1.584 & -0059 \\
\hline F5 & 0.829 & 0.804 & 1.683 & 0024 \\
\hline F6 & 0.310 & 0.479 & 0.789 & -0.169 \\
\hline $\mathrm{F7}$ & 0.765 & 0.769 & 1.534 & $-0,004$ \\
\hline F8 & 0.709 & 0.760 & 1.538 & 0001 \\
\hline $\mathrm{Fg}$ & 0661 & 0.666 & 1.36 & -0005 \\
\hline F10 & 1.000 & 0.553 & 1.553 & 0.447 \\
\hline
\end{tabular}

FIGURE 2. RELATION TABLE OF D-R AND D+R

With the rapid economic development, material production surplus, supply is greater than demand, product or service homogeneity is serious, and the difference is not obvious. In this case, the brand will undoubtedly become the main symbol of the distinction between similar products. Having a brand will not only bring a stronger competitive edge, but also a premium business, resulting in value-added. The establishment of a product brand should be a long-term policy that businesses must adhere to. The higher the visibility of the brand, the more consumers recognized and trusted, the easier to spread, its impact on the promotion is the largest. Public relations activities will play a special role in the promotion. It emphasizes to establish and maintain a good relationship to the public, building proper external environment that is good for their promotions. Public relations activities also build the corporate images and stimulates consumers' interests in the enterprise and its product, to improve the result of product sale. So, public relations 
activities are the second important factor behind product brand. Beverage industry in the promotion and spreading the brand image commonly use the way of celebrity endorsement, with celebrity "fame" to improve the consumer audience attention to the product. This method not only attracts consumers to know the brand, but also improves the brand's popularity to achieve the purpose of promotion, which is the third most important factor affecting the promotion. Now the quality of the staff on the overall requirements improves. the sales staff is no exception. Consumers are more personalized features, with the technical means of progress, consumers access to information from more and more channels, therefore they are less dependent on sales staff, which result in the least importance of salesperson quality among all the factors. When the enterprises carry out promotional activities, they often use multi-way publicity. Retail enterprises in the display of goods often show the map, so compared to other factors, the display of goods on the promotion as an impact is relatively weak. It is only more important than the quality of sales staff.

From the perspective of reason degree, business promotion activities have a large influence on other factors. When doing promotions, companies should first determine the plan for this factor. Product brand (F1), celebrity effect (F4), merchandise display (F3) and sales staff quality (F6) have a negative reason degree, which suggests that these factors are easily influenced by other factors. Business promotion is the most popular form of promotion, often used in short-term promotional activities. As an effective form, compared with other factors, it can quickly generate incentives to achieve the purpose of the transaction. Its effectiveness has a greater impact on other factors. Therefore, enterprises in the promotion must first determine the business promotion program to achieve the promotional effect, publicity product brand. Product brand, celebrity effect, merchandise display and sales staff quality are very susceptible to other factors. Therefore, enterprises in determining the promotion program cannot ignore the impact of other factors on these factors, should take integrity into consideration. Only by doing this can enterprises build competitive brand and good corporate image, and finally improve promotion effectiveness.

\section{CONCLUSION}

These findings can provide a basis for business decision makers to make decisions. Using artificial intelligence, combined with the idea of triangular fuzzy numbers to discuss these ten factors and to analyze rationally their intelligent relations between each other, we can obtain from the result that the usage and simplicity of this method is approved, which suggests that this method can be spread to other fields, such as decision making problem in agriculture, biomedical, transportation and so on, providing research fellows or company decision maker a scientific, simple, easy and effective decision-making analysis method.

\section{References}

[1] P. Kotler, and K. I. Keller, K.L. Marketing Management [M]. trans by Wang, Yonggui. Beijing: China Renmin University Press, 2009: 588.

[2] Y. Luo, and Z. Lu. "Game Analysis and Promotional Reform of Consumer Goods Promotional Portfolio" [J]. Nankai Management Review, 2004, 7 (3): 24 - 28.

[3] Y. Zhang, and P. Peng. "Deep Analysis of Pushy Promotional Idea Transformation" [J]. Financial and Trade Research, 2009 (3): 150 - 151.

[4] Q. Wang, and R. Chen. "Influencing Factors and Interaction of Integral Promotional Effect" [J]. Marketing and Market, 2010 (1): 4

[5] Y. Dong, and W. Li. "A Study on the Impact of PostCrisis Sales Promotion on Consumers' Willingness to Purchase" [J]. Statistics and Decisions, 2010 (1): 4.

[6] Y. Zeng, L. E. W. Yurong, and F. Zhao. "The Effect of the Promotional Form on the Consumer Reference Price" [J]. Statistics and Decisions, 2011 (7): 51 - 54.

[7] J. Li, L. Zhou, and H. Wang. "Retailer 's Promotional Time Decision Model in Multi - Product Cooperative Promotion Model" [J]. China Management Science, 2013, 21 (4): 89 - 95.

[8] Y. Li, and F. Jing. "The Impact of Merchant Promotional Stimulation on Consumers' Impulsive Post-Purchase Satisfaction - The Way of Promotion and the Change of Time" [J]. Management Reviews, 2014, 26 (3): $81-88$.

[9] Y. Lin. "A Preliminary Study on the Promotion Strategy of Enterprise 's Product" [J]. Modern Economic Information, 2014 (12): 75.

[10] H. Zeng, and L. Hao. "A Study on the Impact of Different Promotional Representations on Customer Brand Loyalty" [J]. Soft Sceince, 2015, 29 (5): 116 120.

[11] H-H. Liu, and Y-Y Chiu. "Sales framing, mental accounting, and discount assignments" [J]. Asia Pacific Management Review, 2015 (20): 201 - 209.

[12] A. Gabus, and A.E. Fontel. "World problems, an invitation to further thought within the framework of DEMATEL". Geneva, Switzerland: Battelle Geneva Research Centre.consumer research, 1987, pp189-199. 